\title{
Effects of Pirenzepine on Dai-kenchu-to-Induced Elevation of the Plasma Neuropeptide Levels in Humans
}

\author{
Yuhki Sato, * Shin Inoue, Fumihiko Katagiri, Hiroki Itoh, and Masaharu Takeyama \\ Department of Clinical Pharmacy, Oita University Hospital; Hasama-machi, Oita 879-5593, Japan. \\ Received May 13, 2005; accepted September 2, 2005
}

\begin{abstract}
Dai-kenchu-to has been used for the treatment of abdominal obstructions, including bowel obstructions and a feeling of coldness in the abdomen. We reported that Dai-kenchu-to increases plasma neuropeptide [motilin, vasoactive intestinal polypeptide (VIP), serotonin, calcitonin gene-related peptide (CGRP), and substance PJ-like immunoreactive substances (IS) levels and that its pharmacologic effects on the gastrointestine are due to changes in gastrointestinal mucosa-regulatory peptide levels. We examined the effects of the selective $M_{1}$ muscarinic receptor antagonist pirenzepine on the elevation of Dai-kenchu-to-induced plasma neuropeptide (gastrin, motilin, somatostatin, VIP, CGRP, substance P)-IS levels in human volunteers and the area under the plasma neuropeptide concentration-time curve from 0 to $240 \mathrm{~min}\left(A U C_{0 \rightarrow 240 \mathrm{~min}}\right)$, which were calculated from the plasma neuropeptide concentration-time curves from each volunteers. Oral pretreatment with pirenzepine reduced the Dai-kenchu-to-induced elevation of plasma motilin and VIP-IS levels and $A U C_{0 \rightarrow 240 \mathrm{~min}}$. Combined treatment with Dai-kenchu-to and pirenzepine increased plasma somatostatin-IS levels and decreased plasma gastrin-IS levels and had no effects on plasma CGRP- and substance P-IS levels and $A U C_{0 \rightarrow 240 \text { min }}$ compared with administration of Dai-kenchu-to alone. Dai-kenchu-to appeared to induce the release of motilin and VIP into plasma mainly through the activation of $M_{1}$ muscarinic receptors, and pirenzepine may affect the pharmacologic action of Daikenchu-to by elevation of plasma motilin and VIP levels.
\end{abstract}

Key words Dai-kenchu-to; pirenzepine; neuropeptide; $M_{1}$ muscarinic receptor

Dai-kenchu-to (Da-Jian-Zhong-Tang), a traditional Japanese Kampo medicine, is prepared from three different Chinese crude drugs: ninjin (Ginseng radix), sanshou (Zanthoxyli fructus), and kankyou (Zingiberis siccaatum rhizome). Dai-kenchu-to has been used for the treatment of abdominal obstructions, including bowel obstructions and a feeling of coldness in the abdomen. Dai-kenchu-to has recently been evaluated for its clinical usefulness in the treatment and prevention of uncomplicated postoperative adhesive intestinal obstruction and its clinical efficacy has been reported. ${ }^{1)}$ It has been reported that the action of Dai-kenchuto is related to both increments in gastrointestinal motility and intestinal blood flow. ${ }^{2-4)}$ We confirmed that the administration of Dai-kenchu-to causes significant increases in the levels of motilin, vasoactive intestinal polypeptide (VIP), serotonin, calcitonin gene-related peptide (CGRP), and substance $\mathrm{P}$ in human plasma. ${ }^{5-7)}$ These results indicate that the gastrointestinal motor activity of Dai-kenchu-to is closely related to changes in these neuropeptides in human plasma.

Nervous mechanisms are important for the regulation of gastrointestinal motility and blood flow. A number of neuropeptides such as CGRP, substance P, and VIP have been localized immunohistochemically in sensory nerves innervating the gastrointestinal tract. ${ }^{8}$ The release of these peptides is controlled by acetylcholine $(\mathrm{ACh})$ from the preganglionic fibers of the parasympathetic nerve. ${ }^{9-11)}$ Muscarinic receptors are also present on the membrane of motilin-secreting cells, and ACh is a major regulator of motilin release in the gastrointestine. $^{12-15)}$

Pirenzepine, an antagonist specific for muscarinic $\mathrm{M}_{1}$ receptors, suppresses acid output and is used to treat gastritis and peptic ulcers clinically. ${ }^{16)}$ It has also been shown that this drug suppresses the elevation of serum gastrin levels by acting directly or indirectly on gastrin cells (G cells). ${ }^{17,18)}$ In this study, we examined the effects of pirenzepine on Dai- kenchu-to-induced elevation of plasma gastrin-, motilin-, somatostatin-, VIP-, CGRP-, and substance P-immunoreactive substance (IS) levels and the area under the plasma neuropeptides concentration-time curve from 0 to $240 \mathrm{~min}$ $\left(A U C_{0 \rightarrow 240 \mathrm{~min}}\right)$ in human volunteers.

\section{VOLUNTEERS, MATERIALS, AND METHODS}

Materials Dai-kenchu-to (TJ-100), prepared as a dried extract powder of Ginseng radix (3.0 g), Zanthoxyli fructus $(2.0 \mathrm{~g})$, and Zingiberis siccaatum rhizome $(5.0 \mathrm{~g})$ were purchased from Tsumura Co. Ltd. (Tokyo, Japan). Pirenzepine (Gastrozepine tablets) was purchased from Boehringer Ingelheim Co. Ltd. (Hyogo, Japan). The placebo was excipient alone (glucose and maltose) for the above formulations.

Synthetic human gastrin I (2-17) was purchased from Sigma Chemicals (St. Louis, MO, U.S.A.) and the VIP fragment peptide was supplied by Professor H. Yajima (Kyoto University, Kyoto, Japan). Antisera to gastrin (A600/R1B), VIP (A6054/R1B), and CGRP were purchased from Biogenesis (Poole, U.K.). Antisera to somatostatin (RA-08-108) and substance P (RA-08-095) were purchased from Cambridge Research Biochemicals (Cambridge, U.K.) and antiserum to motilin (Y121) was purchased from the Yanaihara Institute (Shizuoka, Japan). All other reagents were of analytical grade from commercial sources.

Volunteers Five healthy male volunteers (nonsmokers), aged 26-29 (median 27) years and weighing 55-68 (median weight 62) kg, participated in this study. Each volunteer received information about the scientific purpose of the study, which was approved by the Ethics Committee of Oita Medical University, and gave informed consent for participation. No volunteer had received any medication for 1 month before the study, and there were at least 3-month intervals between participation in other studies. The volunteers had 
participated in more than three similar studies.

Study Schedule Dai-kenchu-to or placebo was administered orally alone or $1 \mathrm{~h}$ after oral administration of pirenzepine $75 \mathrm{mg}$ as a single dose of $7.5 \mathrm{~g}$ with water. Venous blood samples $(10 \mathrm{ml})$ from a forearm vein were taken for enzyme immunoassay (EIA) of the levels of neuropeptides. Samples were taken before, and at 20, 40, 60, 90, 120, 180, and $240 \mathrm{~min}$ after administration of the drugs (Fig. 1). All volunteers ate lunch $(11: 30-12: 00)$ and the study was carried out from 14:00 ( $2 \mathrm{~h}$ after lunch) to 18:00.

EIAs of Gastrin, Somatostatin, Motilin, VIP, CGRP, and Substance $\mathbf{P}$ Blood samples were collected in a chilled tube containing aprotinin $(500 \mathrm{KIU} / \mathrm{ml})$ and ethylenediaminetetraacetic acid (EDTA) $(1.2 \mathrm{mg} / \mathrm{ml})$. After centrifugation, the plasma was diluted with $4 \%$ acetic acid ( $\mathrm{pH} 4.0$ ), loaded onto Sep-Pak $\mathrm{C}_{18}$ cartridges (Millipore Corp., Milford, MA, U.S.A.), and washed with $4 \%$ acetic acid. The peptides in the plasma were eluted with $70 \%$ acetnitrile in $0.5 \%$ acetic acid ( $\mathrm{pH} 4.0$ ), lyophilized, and reconstituted to $100 \mu \mathrm{l}$ with the assay buffer and subjected to EIA. For the EIA system, plasma samples were concentrated five-fold with SepPak $\mathrm{C}_{18}$ cartridges. The recovery of plasma gastrin-, ${ }^{19)}$ somatostatin-, ${ }^{20)}$ motilin-, ${ }^{21)}$ VIP-, ${ }^{22)}$ CGRP-,${ }^{23)}$ and substance P-IS ${ }^{24)}$ was $>90 \%$ with this extraction procedure (data not shown).

EIAs for gastrin-, somatostatin-, motilin-, VIP-, CGRP-, and substance P-IS were performed as previously described, using a delayed-addition method. ${ }^{12-17)}$ Separation of bound and free antigen was performed on an anti-rabbit IgG (55641, ICN Pharmaceuticals, Ohio, U.S.A.)-coated immunoplates. The fluorescent product 4-methylumbelliferon was measured with an MTP-100F microplate reader (Corona Electric, Ibaraki, Japan). Fragment gastrin I (2-17), human somatostatin, porcine motilin, fragment VIP (11-28), human CGRP (8-37), and substance $\mathrm{P}$ were conjugated with $\beta$-D-galactosidase (Boehringer Mannheim, Mannheim, Germany) with $N$-( $\varepsilon$-maleimidocaproyloxy)-succimide according to the method Kitagawa et al. ${ }^{25)}$ The EIAs for gastrin, somatostatin, motilin, VIP, CGRP, and substance P were specific and highly sensitive to detection limits of $0.04,0.10$, $0.80,1.00,0.08$, and $0.40 \mathrm{fmol} /$ well, respectively.

Data Analysis Total release of peptides was calculated as the areas under the plasma concentration-time curves $\left(A U C_{0 \rightarrow 240 \mathrm{~min}}\right)$ using the trapezoidal method. All values are expressed as mean \pm S.D. (pg/ml). Comparisons of plasma peptide levels among blood sampling times were made with analysis of variance and the Mann-Whitney $U$-test. Values of $p<0.01$ or $p<0.05$ were considered to represent a statistically significant difference.

\section{RESULTS}

Effects of Dai-kenchu-to, with or without Pirenzepine Pretreatment, on Plasma Gastrin-IS In the healthy volunteers, Dai-kenchu-to alone had no effect on plasma gastrin-IS levels compared with placebo. Gastrin-IS levels decreased significantly at $20 \mathrm{~min}$ after the administration of Dai-kenchu-to with pirenzepine pretreatment $(19.2 \pm 10.3 \mathrm{pg} /$ $\mathrm{ml})$, compared with Dai-kenchu-to alone $(40.4 \pm 12.8 \mathrm{pg} / \mathrm{ml})$ or placebo $(50.8 \pm 9.7 \mathrm{pg} / \mathrm{ml})$ (Fig. 2). The release of gastrin $\left(A U C_{0 \rightarrow 240 \mathrm{~min}}\right)$ after the administration of placebo, Dai-ken-
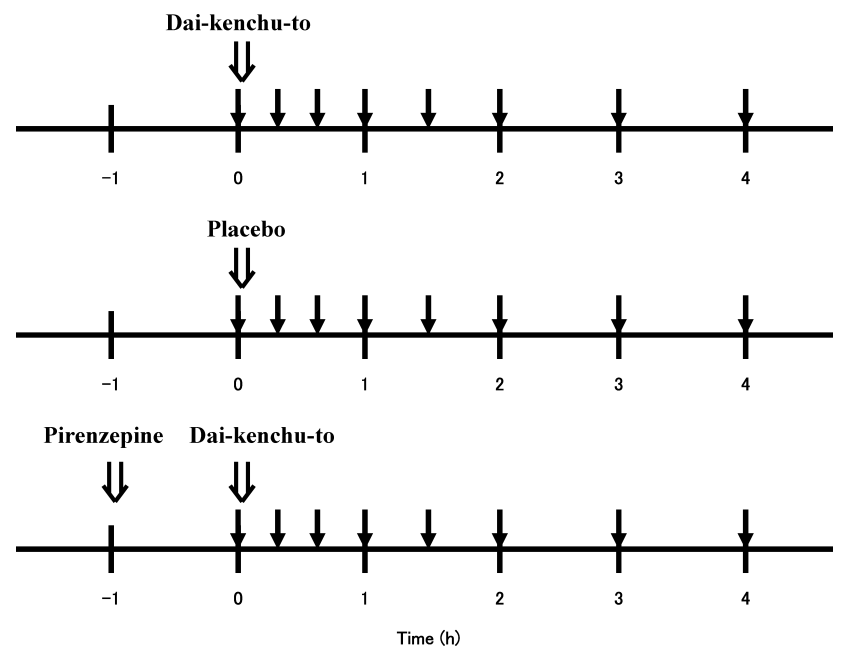

Fig. 1. Administration (Open Arrow) and Sampling Times (Closed Arrow) for Determination of Plasma Peptide Concentrations in Healthy Volunteers

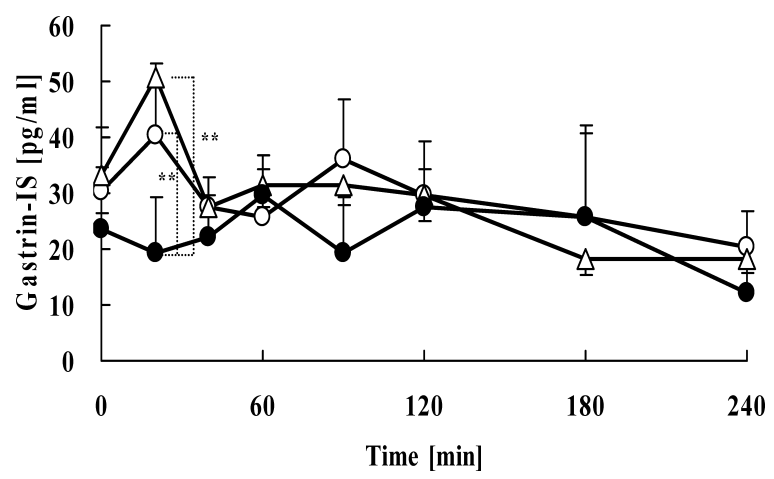

Fig. 2. Plasma Gastrin-IS Levels in Healthy Volunteers after Oral Administration of Dai-kenchu-to $7.5 \mathrm{~g}$ with $(\mathbf{O})$ or without $(\bigcirc)$ Pirenzepine Pretreatment $(75 \mathrm{mg}$ p.o.) or Placebo $(\triangle)$

Each value represents mean \pm S.D., $n=5$. Comparisons of plasma peptide levels among blood sampling times were made with analysis of variance $(* * p<0.01)$.

chu-to, and Dai-kenchu-to with pirenzepine pretreatment were similar (Table 1A).

Effects of Dai-kenchu-to, with or without Pirenzepine Pretreatment, on Plasma Motilin-IS In the healthy volunteers, Dai-kenchu-to caused increases in plasma motilin-IS levels at 40 and $180 \mathrm{~min}(102.7 \pm 15.9 \mathrm{pg} / \mathrm{ml}$ at $40 \mathrm{~min}$, and $119.7 \pm 16.9 \mathrm{pg} / \mathrm{ml}$ at $120 \mathrm{~min}$, respectively) compared with placebo. Plasma motilin-IS levels decreased significantly at 40 and $180 \mathrm{~min}$ after the administration of Dai-kenchu-to with pirenzepine pretreatment $(36.4 \pm 21.2 \mathrm{pg} / \mathrm{ml}$ at $40 \mathrm{~min}$ and $43.6 \pm 25.8 \mathrm{pg} / \mathrm{ml}$ at $180 \mathrm{~min}$, respectively), compared with Dai-kenchu-to alone (Fig. 3). The release of motilin $\left(A U C_{0 \rightarrow 240 \mathrm{~min}}\right)$ increased significantly after the administration of Dai-kenchu-to alone $(21057.4 \pm 3017.4 \mathrm{pg} \mathrm{min} / \mathrm{ml})$ and decreased after the administration of Dai-kenchu-to with pirenzepine pretreatment $(11999.4 \pm 2482.6 \mathrm{pg} \mathrm{min} / \mathrm{ml})$ compared with placebo (16601.4 $\pm 1406.5 \mathrm{pg} \mathrm{min} / \mathrm{ml})$ (Table 1B).

Effects of Dai-kenchu-to, with or without Pirenzepine Pretreatment, on Plasma Somatostatin-IS In the healthy volunteers, Dai-kenchu-to had no effect on plasma somatostatin-IS levels compared with placebo. Somatostatin-IS levels increased significantly at $60 \mathrm{~min}$ after the administration of Dai-kenchu-to with pirenzepine pretreatment (30.6 \pm 
Table 1. Total Amount of Gastrin- (A), Motilin- (B), Somatostatin- (C), VIP- (D), CGRP- (E), and Substance P-IS (F) Released after the Administration of Dai-kenchu-to to 5 Healthy Volunteers

(A)

\begin{tabular}{lrrrrrrrr}
\hline \hline & \multicolumn{9}{c}{ Subject numbers } & & & \\
\multirow{2}{*}{$\begin{array}{c}\text { Gastrin } A U C_{0 \rightarrow 240} \\
(\text { pg min } / \mathrm{ml})\end{array}$} & 1 & 2 & 3 & 4 & 5 & & \\
\cline { 2 - 7 } & 7181.5 & 6043.0 & 7515.0 & 9172.5 & 4427.5 & 6867.9 & 1765.2 \\
\hline $\begin{array}{c}\text { Dai-kenchu-to } \\
\text { Dai-kenchu-to } \\
\text { with pirenzepine }\end{array}$ & 6593.0 & 6211.0 & 5895.5 & 6909.5 & 4480.0 & 6017.8 & 941.2 \\
Placebo & 7531.0 & 6072.3 & 6894.5 & 8553.5 & 6487.5 & 7107.8 & 971.0
\end{tabular}

(B)

\begin{tabular}{|c|c|c|c|c|c|c|c|}
\hline \multirow{2}{*}{$\begin{array}{l}\text { Motilin } A U C_{0 \rightarrow 240} \\
\quad(\mathrm{pg} \mathrm{min} / \mathrm{ml})\end{array}$} & \multicolumn{5}{|c|}{ Subject numbers } & \multirow{2}{*}{ Mean } & \multirow{2}{*}{ S.D. } \\
\hline & 1 & 2 & 3 & 4 & 5 & & \\
\hline Dai-kenchu-to & 18095.5 & 22094.5 & 25428.5 & 18339.0 & 21329.5 & $21057.4 * *$ & 3017.4 \\
\hline $\begin{array}{l}\text { Dai-kenchu-to } \\
\text { with pirenzepine }\end{array}$ & 10072.5 & 14084.5 & 11370.0 & 9399.0 & 15071.0 & $11999.4^{* *}$ & 2482.6 \\
\hline Placebo & 17302.5 & 15576.5 & 18661.5 & 16290.0 & 15176.5 & 16601.4 & 1406.5 \\
\hline
\end{tabular}

(C)

\begin{tabular}{lccccccc}
\hline \hline $\begin{array}{c}\text { Somatostatin } \\
A U C_{0 \rightarrow 240} \\
(\mathrm{pg} \text { min/ml) }\end{array}$ & 1 & 2 & 3 & 4 & 5 & & \\
\cline { 2 - 7 } & \multicolumn{6}{c}{ Subject numbers } & S.D. \\
\hline $\begin{array}{c}\text { Dai-kenchu-to } \\
\text { Dai-kenchu-to } \\
\text { with pirenzepine }\end{array}$ & 2254.0 & 5437.0 & 4708.0 & 4402.5 & 4733.5 & 4307.0 & 1208.7 \\
Placebo & 1417.5 & 2341.0 & 2365.0 & 2717.5 & 2601.0 & 2288.4 & 512.1 \\
\hline
\end{tabular}

(D)

\begin{tabular}{|c|c|c|c|c|c|c|c|}
\hline \multirow{2}{*}{$\begin{array}{l}\text { VIP } A U C_{0 \rightarrow 240} \\
(\mathrm{pg} \mathrm{min} / \mathrm{ml})\end{array}$} & \multicolumn{5}{|c|}{ Subject numbers } & \multirow{2}{*}{ Mean } & \multirow{2}{*}{ S.D. } \\
\hline & 1 & 2 & 3 & 4 & 5 & & \\
\hline Dai-kenchu-to & 3368.0 & 2783.5 & 2846.5 & 2690.5 & 2836.0 & $2904.9^{* *}$ & 266.1 \\
\hline $\begin{array}{l}\text { Dai-kenchu-to } \\
\text { with pirenzepine }\end{array}$ & 2434.0 & 2203.0 & 1577.5 & 1042.0 & 1681.0 & 1787.5 & 548.1 \\
\hline Placebo & 2250.0 & 1787.0 & 1607.0 & 2237.0 & 2194.5 & 2015.1 & 298.0 \\
\hline
\end{tabular}

(E)

\begin{tabular}{|c|c|c|c|c|c|c|c|}
\hline \multirow{2}{*}{$\begin{array}{l}\mathrm{CGRP} A U C_{0 \rightarrow 240} \\
\quad(\mathrm{pg} \mathrm{min} / \mathrm{ml})\end{array}$} & \multicolumn{5}{|c|}{ Subject numbers } & \multirow{2}{*}{ Mean } & \multirow{2}{*}{ S.D. } \\
\hline & 1 & 2 & 3 & 4 & 5 & & \\
\hline Dai-kenchu-to & 7892.0 & 18209.0 & 12489.0 & 6566.5 & 6660.0 & $10363.3^{*}$ & 5007.8 \\
\hline $\begin{array}{l}\text { Dai-kenchu-to } \\
\text { with pirenzepine }\end{array}$ & 4692.5 & 5175.5 & 2967.5 & 5110.0 & 2834.0 & 4155.9 & 1161.6 \\
\hline Placebo & 6780.0 & 5410.0 & 6240.0 & 6440.0 & 4286.5 & 5831.3 & 1000.2 \\
\hline
\end{tabular}

(F)

\begin{tabular}{|c|c|c|c|c|c|c|c|}
\hline \multirow{2}{*}{$\begin{array}{c}\text { Substance P } \\
A U C_{0 \rightarrow 240} \\
(\mathrm{pg} \mathrm{min} / \mathrm{ml})\end{array}$} & \multicolumn{5}{|c|}{ Subject numbers } & \multirow{2}{*}{ Mean } & \multirow{2}{*}{ S.D. } \\
\hline & 1 & 2 & 3 & 4 & 5 & & \\
\hline Dai-kenchu-to & 7972.5 & 10360.0 & 18207.5 & 9296.0 & 9172.0 & 11001.6 & 4116.1 \\
\hline $\begin{array}{l}\text { Dai-kenchu-to } \\
\text { with pirenzepine }\end{array}$ & 8164.5 & 6408.5 & 7934.5 & 11853.5 & 10502.0 & 8972.6 & 2176.2 \\
\hline Placebo & 6579.0 & 9131.5 & 9275.5 & 8785.5 & 7935.5 & 8341.4 & 1114.1 \\
\hline
\end{tabular}

Comparisons of each $A U C_{0 \rightarrow 240 \mathrm{~min}}$ were made with the Mann-Whitney $U$-test. $* * p<0.01, * p<0.05$.

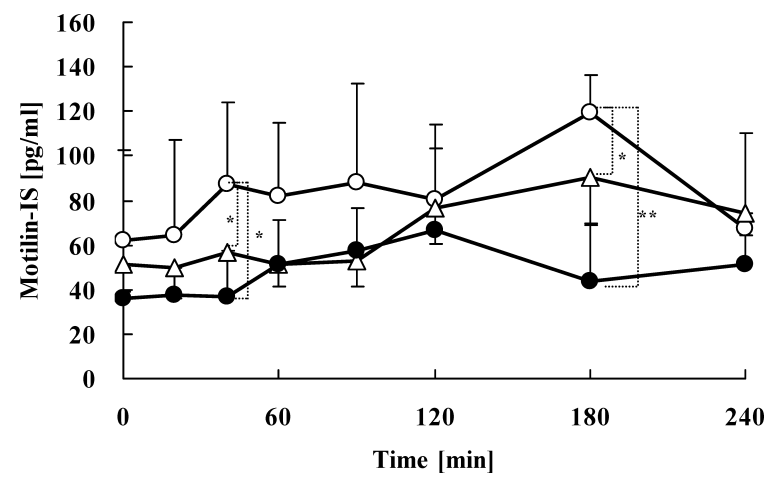

Fig. 3. Plasma Motilin-IS Levels in Healthy Volunteers after Oral Administration of Dai-kenchu-to $7.5 \mathrm{~g}$ with $(\bigcirc)$ or without $(\bigcirc)$ Pirenzepine Pretreatment (75 mg p.o.) or Placebo $(\triangle)$

Each value represents mean \pm S.D., $n=5$. Comparisons of plasma peptide levels among blood sampling times were made with analysis of variance $(* * p<0.01, * p<$ $0.05)$.

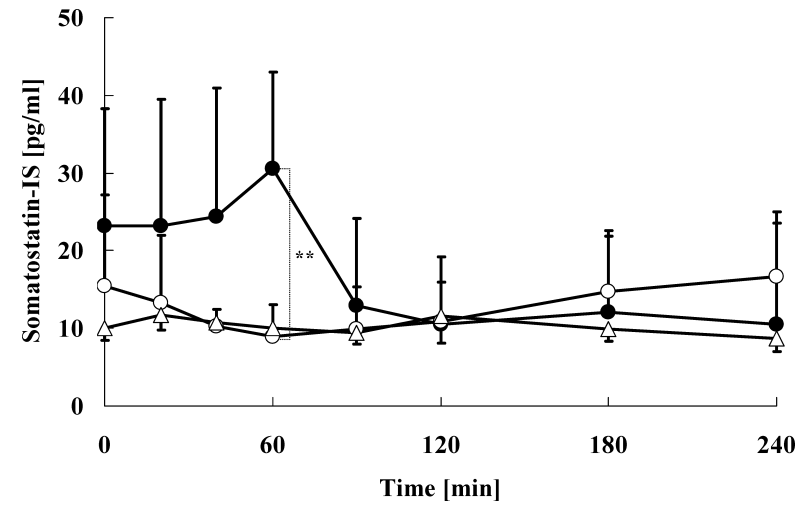

Fig. 4. Plasma Somatostatin-IS Levels in Healthy Volunteers after Oral Administration of Dai-kenchu-to $7.5 \mathrm{~g}$ with $(\mathbf{O})$ or without $(\bigcirc)$ Pirenzepine Pretreatment ( $75 \mathrm{mg}$ p.o.) or Placebo $(\triangle)$

Each value represents mean \pm S.D., $n=5$. Comparisons of plasma peptide levels among blood sampling times were made with analysis of variance $(* * p<0.01)$.

$10.2 \mathrm{pg} / \mathrm{ml})$, compared with Dai-kenchu-to alone $(8.9 \pm$ $4.1 \mathrm{pg} / \mathrm{ml})$ or placebo $(10.0 \pm 1.2 \mathrm{pg} / \mathrm{ml})$ (Fig. 4). The release of somatostatin $\left(A U C_{0 \rightarrow 240 \mathrm{~min}}\right)$ did not change significantly after the administration of Dai-kenchu-to alone or Daikenchu-to with pirenzepine pretreatment, compared with placebo (Table 1C).

Effects of Dai-kenchu-to, with or without Pirenzepine Pretreatment, on Plasma VIP-IS In the healthy volunteers, Dai-kenchu-to caused increases in plasma VIP-IS levels at $40,120,180$, and $240 \mathrm{~min}(14.0 \pm 5.4 \mathrm{pg} / \mathrm{ml}$ at $40 \mathrm{~min}$, $21.2 \pm 7.5 \mathrm{pg} / \mathrm{ml}$ at $120 \mathrm{~min}, 9.3 \pm 2.5 \mathrm{pg} / \mathrm{ml}$ at $180 \mathrm{~min}$, and $10.4 \pm 5.0 \mathrm{pg} / \mathrm{ml}$ at $240 \mathrm{~min}$ ) compared with placebo. Plasma VIP-IS levels decreased significantly at 120, 180, and 240 min after the administration of Dai-kenchu-to with pirenzepine pretreatment $(7.5 \pm 12.0 \mathrm{pg} / \mathrm{ml}$ at $120 \mathrm{~min}, 5.3 \pm 1.8 \mathrm{pg} /$ $\mathrm{ml}$ at $180 \mathrm{~min}$ and $7.2 \pm 0.8 \mathrm{pg} / \mathrm{ml}$ at $240 \mathrm{~min}$ ) compared with Dai-kenchu-to alone (Fig. 5). The release of VIP $\left(A U C_{0 \rightarrow 240 \mathrm{~min}}\right)$ increased significantly after Dai-kenchu-to alone $(2904.9 \pm 266.1 \mathrm{pg} \mathrm{min} / \mathrm{ml})$ but did not change after the administration of Dai-kenchu-to with pirenzepine pretreatment $(1787.5 \pm 548.1 \mathrm{pg} \mathrm{min} / \mathrm{ml})$ compared with placebo (2015.1 $\pm 298.0 \mathrm{pg} \mathrm{min} / \mathrm{ml}$ ) (Table 1D).

Effects of Dai-kenchu-to, with or without Pirenzepine Pretreatment, on Plasma CGRP-IS In the healthy volun- 


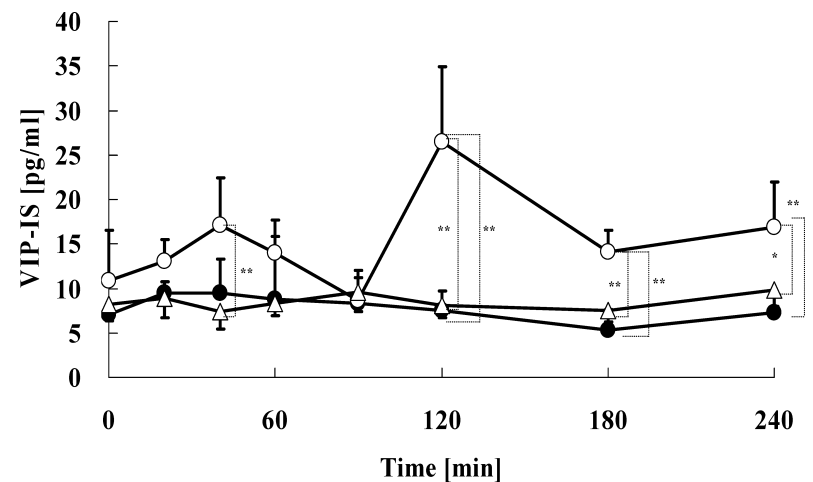

Fig. 5. Plasma VIP-IS Levels in Healthy Volunteers after Oral Administration of Dai-kenchu-to $7.5 \mathrm{~g}$ with $(\bigcirc)$ or without $(\bigcirc)$ Pirenzepine Pretreatment (75 mg p.o.) or Placebo $(\triangle)$

Each value represents mean \pm S.D., $n=5$. Comparisons of plasma peptide level among blood sampling times were made with analysis of variance $(* * p<0.01, * p<$ $0.05)$.

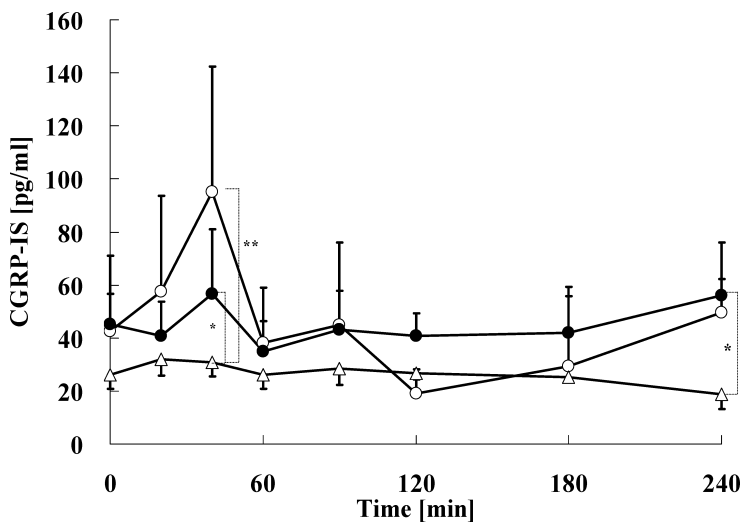

Fig. 6. Plasma CGRP-IS Levels in Healthy Volunteers after Oral Administration of Dai-kenchu-to $7.5 \mathrm{~g}$ with $(\bigcirc)$ or without $(\bigcirc)$ Pirenzepine Pretreatment $(75 \mathrm{mg}$ p.o.) or Placebo $(\triangle)$

Each value represents mean \pm S.D., $n=5$. Comparisons of plasma peptide levels among blood sampling times were made with analysis of variance $(* * p<0.01, * p<$ $0.05)$.

teers, Dai-kenchu-to caused increases in plasma CGRP-IS levels at $40 \mathrm{~min}(95.1 \pm 47.3 \mathrm{pg} / \mathrm{ml}$ at $40 \mathrm{~min})$ compared with placebo. Dai-kenchu-to with pirenzepine pretreatment caused increases in plasma CGRP-IS levels at 40 and $240 \mathrm{~min}$ $(56.7 \pm 24.4 \mathrm{pg} / \mathrm{ml}$ at $40 \mathrm{~min}$ and $56.0 \pm 6.3 \mathrm{pg} / \mathrm{ml}$ at $240 \mathrm{~min})$ compared with placebo. After the administration of Daikenchu-to with pirenzepine pretreatment or Dai-kenchu-to alone, no significant changes were observed in CGRP-IS levels after administration of test drugs (Fig. 6). The release of CGRP $\left(A U C_{0 \rightarrow 240 \min }\right)$ increased significantly after Dai-kenchu-to alone but did not change after the administration of Dai-kenchu-to with pirenzepine pretreatment, compared with placebo (Table 1E).

Effects of Dai-kenchu-to, with or without Pirenzepine Pretreatment, on plasma Substance P-IS In the healthy volunteers, Dai-kenchu-to caused increases in plasma substance P-IS levels at 20, 40, and $60 \mathrm{~min}(57.5 \pm 31.6 \mathrm{pg} / \mathrm{ml}$ at $20 \mathrm{~min}, 63.1 \pm 30.7 \mathrm{pg} / \mathrm{ml}$ at $40 \mathrm{~min}$ and $52.9 \pm 9.4 \mathrm{pg} / \mathrm{ml}$ at $60 \mathrm{~min})$ compared with placebo. Dai-kenchu-to with pirenzepine pretreatment caused increases in plasma substance PIS levels at 20,40 , and $60 \mathrm{~min}(40.5 \pm 11.9 \mathrm{pg} / \mathrm{ml}$ at $20 \mathrm{~min}$, $36.0 \pm 12.8 \mathrm{pg} / \mathrm{ml}$ at $40 \mathrm{~min}$ and $39.0 \pm 19.2 \mathrm{pg} / \mathrm{ml}$ at $60 \mathrm{~min})$ compared with placebo. Plasma substance P-IS levels after

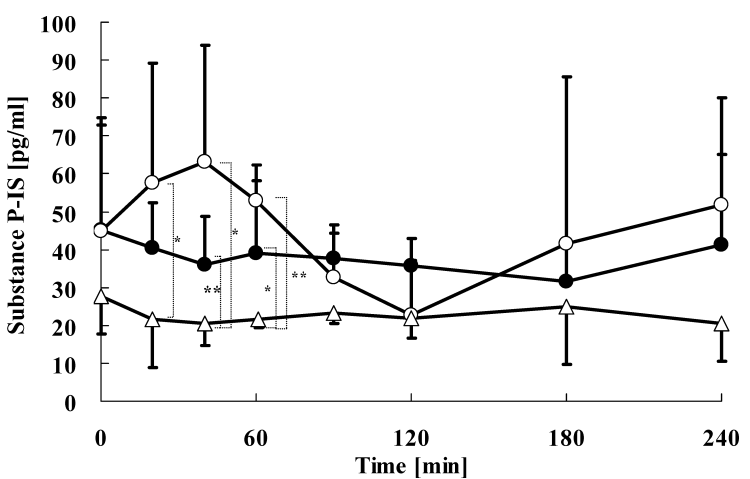

Fig. 7. Plasma Substance P-IS Levels in Healthy Volunteers after Oral Administration of Dai-kenchu-to $7.5 \mathrm{~g}$ with $(\mathbf{O})$ or without $(\bigcirc)$ Pirenzepine Pretreatment ( $75 \mathrm{mg}$ p.o.) or Placebo $(\triangle)$

Each value represents mean \pm S.D., $n=5$. Comparisons of plasma peptide levels among blood sampling times were made with analysis of variance $(* * p<0.01, * p<$ $0.05)$.

the administration of Dai-kenchu-to with pirenzepine pretreatment compared with Dai-kenchu-to alone did not change significantly after the administration of test drugs (Fig. 7). The release of substance $\mathrm{P}\left(A U C_{0 \rightarrow 240 \mathrm{~min}}\right)$ did not change after either Dai-kenchu-to alone or Dai-kenchu-to with pirenzepine pretreatment compared with placebo (Table 1F).

\section{DISCUSSION}

Dai-kenchu-to improves gastrointestinal motility and increases gastrointestinal mucosal blood flow. It is thought that the action of this medicine is involved in elevated neuropeptide (motilin, VIP, CGRP, and substance P) levels in the gastrointestinal tract. Some neuropeptides-producing cells or neurons receive cholinergic inputs via muscarinic receptors from intrinsic neurons in the gastrointestinal tract. It is therefore of interest to examine the effects of cholinergic antagonists on Dai-kenchu-to-induced neuropeptide release. We examined the effects of the $\mathrm{M}_{1}$ muscarinic receptor antagonist pirenzepine on Dai-kenchu-to induced-plasma gastrin-, motilin-, somatostatin-, VIP, CGRP-, and substance P-IS levels in healthy volunteers.

Gastrin was first detected in extracts of pyloric antral mu$\operatorname{cosa}^{26)}$ Gastrin stimulates gastric acid secretion involving $G$ cells, and it is associated with a mechanism of gastrointestinal motility involving the cholinergic nervous system. ${ }^{27)}$ In our results, temporary elevations in plasma gastrin-IS levels were seen after the administration of both Dai-kenchu-to and placebo at $20 \mathrm{~min}$. It is thought that the changes in gastrin-IS levels are due to the action of Dai-kenchu-to and placebo on the gastric mucosal $\mathrm{G}$ cells and not to the specific action of Dai-kenchu-to. ${ }^{5)}$ The administration of Dai-kenchu-to with pirenzepine pretreatment decreased plasma gastrin-IS levels, although not as markedly as the administration of Daikenchu-to alone compared with placebo. It was thought that temporary increases in plasma gastrin-IS levels were suppressed by pirenzepine.

Motilin is found in specific endocrine cells of the upper small intestine of hogs. ${ }^{28)}$ It strongly stimulates fundic pouch activity and plays an important physiologic role in intestinal contractility. ${ }^{29)}$ Motilin is one of the most important factors controlling the regular occurrence of phase III of interdiges- 
tive migrating contractions. ${ }^{30,31)}$ It has been reported that Dai-kenchu-to stimulates gastrointestinal motility via $\mathrm{ACh}$ release and increases plasma motilin in dogs and humans. ${ }^{5,32)}$ Muscarinic receptors are present on the membrane of motilin-secreting cells, and $\mathrm{ACh}$ is a major regulator of motilin release by acting on $\mathrm{M}_{1}$ or $\mathrm{M}_{3}$ muscarinic receptors. $^{12-15)}$ In our results, the administration of Dai-kenchu-to with pirenzepine pretreatment decreased plasma motilin-IS levels compared with Dai-kenchu-to alone. Our findings suggest that Dai-kenchu-to may stimulate motilin cells mainly via $\mathrm{M}_{1}$ muscarinic receptors.

Somatostatin is a gastrointestinal motility stimulator and functions as an inhibitor of motilin and gastrin release in digestive organs. ${ }^{33-36)}$ In our results, the administration of Daikenchu-to with pirenzepine pretreatment significantly increased plasma somatostatin-IS levels compared with Daikenchu-to alone or placebo, while transient elevations in plasma gastrin-IS were inhibited. Sue et al. reported that pirenzepine acts on somatostatin cells (D cells) to promote somatostatin release, thereby indirectly suppressing gastrin release from $\mathrm{G}$ cells in the stomach. ${ }^{18)}$ In our study, the effects of Dai-kenchu-to with pirenzepine pretreatment on plasma somatostatin- and gastrin-IS might be related to direct or indirect action by pirenzepine.

VIP has a vasodilating effect and is a gastrointestinal motility regulator. VIP is considered to be one of the neurotransmitters released from nonadrenergic, noncholinergic inhibitory neurons in the gastrointestinal tract. ${ }^{37-39)}$ We found that Dai-kenchu-to caused significant increases in plasma VIP-IS levels, as in the report of Nagano et al., ${ }^{6}$ while plasma VIP-IS levels after the administration of Dai-kenchuto with pirenzepine pretreatment showed the same pattern as that observed after the administration of placebo. Previous studies showed that VIP output in response to ACh was greatly inhibited by pirenzepine in blood-perfused ileum and isolated ileal tissues in dogs. ${ }^{9)}$ Thus Dai-kenchu-to may stimulate VIP-producing neurons via $\mathrm{M}_{1}$ muscarinic receptors.

CGRP is a powerful vasoactive substance that is released from the sensory afferent nerve endings in response to gastric mucosal injury in the stomach. ${ }^{40,41)}$ CGRP increases gastric mucosal blood flow as a gastroprotective factor. ${ }^{42}$ In addition, CGRP has a potent effect on gastrointestinal motility and secretion. ${ }^{43)}$ Recently, it has been reported that Daikenchu-to increases intestinal blood flow, which is mainly mediated by CGRP, in rats. ${ }^{4}$ In our study, Dai-kenchu-to significantly raised plasma CGRP-IS levels after administration to healthy volunteers. On the other hand, plasma CGRP-IS levels after the administration of Dai-kenchu-to with pirenzepine pretreatment tended to decrease compared with the administration of Dai-kenchu-to alone. Previous studies demonstrated that CGRP is localized in motor neurons and nerve terminals at the neuromuscular junction, where it coexists with ACh, and that CGRP is a neurotransmitter that may act in conjunction with $\mathrm{ACh}{ }^{44,45)}$ Transforini et al. also reported that the acetylcholinesterase inhibitor caused significant increases in basal plasma levels of CGRP in healthy humans, whereas pirenzepine failed to exert any significant effect. $^{10)}$ This indicates that ACh controls CGRP release from CGRP-containing nerves. Although it has not been demonstrated previously whether Dai-kenchu-to directly stimulates CGRP-containing nerves or indirectly secretes CGRP ac- companied by the stimulation of other secretory cells and mechanisms, the effects of Dai-kenchu-to on CGRP levels might be related in part to $M_{1}$ muscarinic receptor.

Substance P coexists with CGRP in the sensory afferent neurons of the gastrointestinal mucosa and is released with $\mathrm{ACh}$ in response to depolarizing stimulation in the enteric nervous system. ${ }^{46)}$ In the gastrointestinal tract, substance $\mathrm{P}$ is thought to be involved in the control of motility, secretion, and blood flow. ${ }^{47,48)}$ Dai-kenchu-to stimulates substance P release and induces contractions in guinea pig ileum. ${ }^{49}$ Schmidt et al. reported that muscarinic receptors are present on the intrinsic substance P-producing neurons and inhibit the release of substance $\mathrm{P}$ in porcine ileum. ${ }^{11)}$ In our study, Dai-kenchu-to raised plasma substance P-IS levels after administration to healthy volunteers, while plasma substance PIS levels after the administration of Dai-kenchu-to with pirenzepine pretreatment tended to decrease compared with Dai-kenchu-to alone. Although it has not previously been comfirmed whether $\mathrm{M}_{1}$ muscarinic receptors are present on the substance P-producing neurons in the gastrointestinal tract, the effects Dai-kenchu-to on plasma substance P levels might be related in part to $\mathrm{M}_{1}$ muscarinic receptor.

According to the report by Sugiyama et al., ${ }^{50)}$ Dai-kenchuto significantly increases plasma motilin levels in the treatment of diseases of the ileus and its changes might contribute to promoting gastrointestinal motility. Murata et al. also reported that Dai-kenchu-to produces an increase in intestinal blood flow and the administration of the atropine or VIP receptor antagonist partially attenuated the Dai-kenchu-to-induced hyperemia. ${ }^{4}$ ) Therefore the pharmacologic action of Dai-kenchu-to might be partially due to the changes in plasma motilin and VIP. In our results, the coadministration of Dai-kenchu-to with pirenzepine pretreatment caused a significant decrease in plasma motilin and VIP release, compared with Dai-kenchu-to alone. It was estimated that use of pirenzepine might affect the clinical efficacy of Dai-kenchuto, although it is certain whether these effects in healthy volunteers are the same as those in patients clinically. Therefore it is necessary to investigate the effects in patients with a condition such as ileus.

In conclusion, Dai-kenchu-to may increase plasma motilin and VIP levels via $\mathrm{M}_{1}$ muscarinic receptors and coadministration of Dai-kenchu-to with pirenzepine decreases Daikenchu-to induced-motilin and VIP release in human plasma. Although further studies are needed, our findings may be important clinically.

\section{REFERENCES}

1) Seki M., J. Med. Pharm. Soc. (Wakanyaku), 4, $94-99$ (1987).

2) Hayakawa T., Kase Y., Saito K., Hashimoto K., Ishige A., Komatsu Y., Sasaki H., J. Smooth Muscle Res., 35, 55-62 (1999).

3) Murata P., Hayakawa T., Satoh K., Kase Y., Ishige A., Sasaki H., Phytother: Res., 15, 302-306 (2001).

4) Murata P., Kase Y., Ishige A., Sasaki H., Kurosawa S., Nakamura T., Life Sci., 70, 2061-2070 (2002).

5) Nagano T., Itoh H., Takeyama M., Biol. Pharm. Bull., 22, 1131-1133 (1999).

6) Nagano T., Itoh H., Takeyama M., Biol. Pharm. Bull., 23, 352-353 (2000).

7) Sato Y., Katagiri F., Inoue S., Itoh H., Takeyama M., Biol. Pharm Bull., 27, 1875- 1877 (2004).

8) Gibbins I. L., Furness J. B., Costa M., Cell Tissue Res., 248, 417-437 
(1987).

9) Kimura H., Ito S., Ohta T., Asano T., Nakazato Y., J. Auton. Nerv. Syst., 48, 167-174 (1994).

10) Transforini G., Margutti A., Vergnani L., Ambrosio M. R., Valentini A., Rossi R., Portaluppi F., Degli Uberti E. C., J. Clin. Endocrinol. Metab., 78, 763-766 (1994).

11) Schmidt P. T., Holst J. J., Peptides, 18, 373-379 (1997).

12) Fox J. E., Daniel E. E., Jury J., Track N. S., Chiu S., Can. J. Physiol. Pharmacol., 61, 1042-1049 (1983).

13) Nelson D. K., Pieramico O., Dahmen G., Dominguez-Munoz J. E., Malfertheiner P., Alder G., Dig. Dis. Sci., 41, 2006-2015 (1996).

14) Poitras P., Dumont A., Cuber J. C., Trudel L., Peptides, 14, 207-213 (1993).

15) Yamada T., Mizumoto A., Satoh M., Haga N., Itoh Z., Peptides, 18 $673-680$ (1997).

16) Hammer R., Bernie C. P., Birdsall N. J., Burgen A. S., Hulime E. C., Nature (London), 283, 90-92 (1980).

17) Matsuo Y., Seki A., Arzneim.-Forsch., 29, 1028-1035 (1979).

18) Sue R., Toomey M. L., Todisco A., Am. J. Physiol., 248, G184-187 (1985).

19) Takeyama M., Matsuo H., Mori K., Chem. Pharm. Bull., 41, 21972199 (1993).

20) Takeyama M., Yanaga N., Yarimizu K., Ono J., Takaki R., Fujii N., Yajima H., Chem. Pharm. Bull., 38, 456-459 (1990).

21) Naito T., Itoh H., Yasunaga F., Takeyama M., Biol. Pharm. Bull., 25, $327-331$ (2002).

22) Takeyama M., Wakayama K., Takayama F., Kondo K., Fujii N., Yajima H., Chem. Pharm. Bull., 38, 960-962 (1990).

23) Nagano T., Ikawa K., Takeyama M., Jpn. J. Hosp. Pharm., 24, $363-$ 369 (1998).

24) Takeyama M., Mori K., Takayama F., Kondo K., Kitagawa K., Fujii N., Chem. Pharm. Bull., 38, 3494-3496 (1990).

25) Kitagawa T., Shimozono T., Aikawa T., Yoshida T., Nishimura H., Chem. Pharm. Bull., 29, 1130-1135 (1981).

26) Edkins J. S., Cantab M. B., Proc. R. Soc. London Ser., B76, 376 (1905).

27) Szelenyi I., Experientia, 36, 973-974 (1980).

28) Christofides N. D., Bloom S. R., "Motilin," ed. by Bloom S. R., Polak J. M., Gut Hormones, Churchill Livingstone, New York, 1981, pp. 273-279.

29) Brown J. C., Gastroenterology, 52, 225-229 (1967).
30) Itoh Z., Honda R., Hiwatashi K., Takeuchi S., Aizawa I., Takayanagi R., Couch E. F., Scand. J. Gastroenterol., 11, 93-110 (1976).

31) You C. H., Chey W. Y., Lee K. Y., Gastroenterology, 79, 62-66 (1980).

32) Shibata C., Sasaki I., Naito H., Ueno T., Matsuno S., Surgery, 126, 918-924 (1999).

33) Peeters T. L., Janssens J., Vantrappen G. R., Regul. Pept., 5, 209-217 (1983).

34) Poitras P., Steinbach J. H., VanDeventer G., Code C. F., Walsh J. H., Am. J. Physiol., 239, G215-220 (1980).

35) Thor P., Krol R., Konturek S. J., Coy D. H., Schally A. V., Am. J. Physiol., 235, E249-254 (1978).

36) Grider J. R., Arimura A., Makhlouf G. M., Am. J. Physiol., 253, G434- 438 (1987).

37) Andersson P. O., Bloom S. R., Edwards A. V., Järhult J., Mellander S., J. Physiol., 344, 49-67 (1983).

38) Fahrenkrug J., Galbo H., Holst J. J., Schaffalitzky de Muckadell O. B., J. Physiol., 280, 405-422 (1978).

39) Ito S., Kurokawa A., Ohga A., Ohta T., Sawabe K., J. Physiol., 430, $337-353$ (1990).

40) Kinoshita Y., Inui T., Chiba T., J. Clin. Gastroenterol., 17, S-27-32 (1993).

41) Yeoh K. G., Kang J. Y., Yap I., Guan R., Tan C. C., Wee A., Teng C. H., Dig. Dis. Sci., 40, 580-583 (1995).

42) Holzer P., Livingston E. H., Saria A., Guth P. H., Am. J. Physiol., 260, G363-370 (1991).

43) Holzer P., Gastroenterology, 114, 823-839 (1998).

44) Fontaine B., Klarsfeld A., Hokfelt T., Changeux J. P., Neurosci. Lett., 71, 59-65 (1986).

45) Takami K., Kawai Y., Shiosaka S., Brain Res., 328, 386-389 (1985).

46) Hellström P. M., Söder O., Theodorsson E., Gastroenterology, 100, 431-440 (1991).

47) Grider J. R., Am. J. Physiol., 257, G709-714 (1987).

48) Schmidt P. T., Lördal M., Gazelius B., Hellström P. M., Gut, 52, 53 56 (2003).

49) Satoh K., Hashimoto K., Hayakawa T., Ishige A., Kaneko M., Ogihara S., Kurosawa S., Yakabi K., Nakamura T., Jpn. J. Pharmacol., 86, $32-37$ (2001).

50) Sugiyama M., Moriwaki Y., Ito S., Hamahata Y., Fukuda N., Tanaka S., Prog. Med., 1085-1088 (1993). 